\title{
An Automatic Frequency Controller for Kotmale Hydro Power Station using Fuzzy Logic
}

\author{
H.K.A. Chaturanga, Lalith A. Samaliarachchi and M. Lakshitha Weerasinghe
}

\begin{abstract}
During supply demand mismatches, the system frequency can either fall or rise compared with its previous steady state operating value. In such instances, the generator governors either increase or decrease the generation (in accordance with the governor droop setting) to restore the supply demand balance and stop the ensuing frequency change (fall or rise). However, even after the supply demand balance has been restored and the frequency has reached a new steady state value, there can be a frequency error. The governor action assists to minimize the steady state frequency error. However, zeroing the frequency error and bringing the system frequency back to the rated value need adjustment to the "speed reference" of governors. Although this is normally done by Automatic Generation Controllers (AGC) that are on secondary load-frequency control, in Sri Lanka, the frequency controlling act is performed entirely manually through operator intervention. Such manual frequency control has a number of draw backs, including possible operator errors and longer response times. One of the four power stations designated to perform the frequency control function in the Sri Lankan power system is at Kotmale. This paper presents an automatic frequency controller using Fuzzy Logic to carry out frequency controlling at Kotmale power station. The Fuzzy Logic based controller is designed to replace the action of the operator, who presently controls the frequency manually.
\end{abstract}

The paper presents the modeling and the simulation of the existing frequency control system using relevant parameters of the Kotmale governor and the chronological load curve of the Sri Lankan power system. MATLAB/Simulink ${ }^{\mathrm{TM}} 2013$ software package is used to calculate the steady state frequency error. Subsequently, the parameters are fine-tuned and the Fuzzy Logic Controller (FLC) is introduced as a secondary loop frequency controller and the study is repeated. Mamdani type fuzzy inference system is employed here to implement this project because of its simplicity, robustness, reliability and intuitive characteristics. Finally the simulation results using the FLC are compared with the existing frequency controlling system of Kotmale power station to prove that the FLC yields improved control performance.

Keywords: Steady state error, frequency control, fuzzy logic

\section{Introduction}

\section{$1.1 \quad$ Background}

A key objective of a utility is to provide the desired quality of power supply to its customers within a given voltage and frequency tolerance. For optimal performance of equipment and for stable operations, the system frequency must be maintained within certain limits. The nominal frequency in the Sri Lankan power system is $50 \mathrm{~Hz}$. The specified frequency tolerance is within the range of $\pm 1 \%$ of its nominal value. The active power (p) control of a power system in response to power system frequency (f) change is known as the load-frequency (pf) control. The pf control in a power system deals with slow changes to demand as well as sudden disturbances that appear under normal operating conditions owing to the stochastic nature of outages of lines and equipment on the supply-side and connection/disconnection of loads on the customer-side. Generator governors which are on primary automatic load frequency control assist to restore supply demand balance during such disturbances and minimize the ensuing steady state frequency error. However, secondary load frequency control, also known as frequency controlling, is required to bring the frequency back to its nominal value. In Sri Lanka, the latter operation is done manually.

Mr. H. K. A. Chaturanga, B. Tech. Eng. (Hons), Open University of Sri Lanka, Electrical Engineer, WKV Hydro Technique (PVT) Ltd.

Eng. Lalith A. Samaliarachchi, B.Sc. Eng. (Hons) (Moratuwa), M. Eng.(AIT), MIEE(UK), MIE(Sri Lanka), C.Eng Senior Lecturer, Department of Electrical $\mathcal{E}$ Computer Engineering, Open University of Sri Lanka

Eng. M. Lakshitha Weerasinghe, B.Sc. Eng. (Hons) (Moratuwa), MPhil. (Peradeniya), MIE (Sri Lanka), C. Eng, MIEEE, Chief Engineer, Business E Operational Strategy, Ceulon Electricitu Board 
There are four major frequency control generating stations identified by the System Control Centre (SCC) of Ceylon Electricity Board (CEB) situated at Kotmale, Victoria, Laxapana and Samanalawewa which perform manual secondary frequency control. The SCC decides and selects one of these four generating stations to control the system frequency at a given time. The decision of the SCC is dependent on many aspects such as the available water storage capacity, downstream irrigation requirements and transmission line constraints. While the system is on steady state, when a sudden load is added to the power system, stored kinetic energy of turbinegenerators initially contributes in real time to help avoid the sudden imbalance between generation and demand. As a result, turbinegenerator speeds drop. Following the change in turbine speeds, and hence the frequency, governors intervene and adjust the turbine power in accordance with the pre-determined set value, based on governor droop characteristics.

However, even after governors restore supplydemand balance by adjusting the generated power to match the change in demand, the final steady state frequency could still have a steady state error. To zero the frequency error and bring the supply frequency and turbine speeds to rated values, a secondary control system is required. In Sri Lanka, the correction of the steady state frequency is manually done by operators. The operator adjusts generation using "lower" and "raise" commands, by looking at the system frequency display, until the frequency error is brought down to zero. Complete reliance on the skill of a single individual (as the case is during most of the time) to maintain an important parameter like system frequency is dangerous. Further, when the time taken to correct the frequency error is large, it can affect the operation of certain industrial machineries that are sensitive to frequency.

Therefore, in this study an automatic frequency control strategy is proposed to control frequency error by using fuzzy logic technology. This will not only eliminate "operator judgment" and human error, but also improve response time as shown later.

\subsection{Aims and Objectives}

The main aim of this study is to design an intelligent controller using fuzzy logic, to control generation (changing megawatt reference set point based on frequency error) at Kotmale hydro power station. The aim \& objectives of the study comprise of:

- Studying the theoretical background of frequency controlling in a power system.

- Mathematically modeling the existing frequency controlling system at Kotmale, using associated transfer functions.

- Determining the required parameters of the existing power system.

- Building up a simulation model using MATLAB/Simulink software for the existing frequency controlling system.

- Analyzing the behavior of the model with disturbances and validate it with frequency deviations.

- Designing a fuzzy logic controller to achieve zero steady state frequency error.

- Simulating and designing a fuzzy logic controller using MATLAB/Simulink and comparing the results.

\section{Existing System}

\subsection{Existing Frequency Controlling Method at the Kotmale Hydro Power Plant}

In Sri Lanka, one of the four frequency controlling stations controls the system frequency at a time, while other stations are operated on a fixed output as determined by the SCC. The "master" frequency controlling station selected for this study is the 67MW unit of Kotmale. Speed droop characteristics of Kotmale hydro power plant are shown in Figure 1.

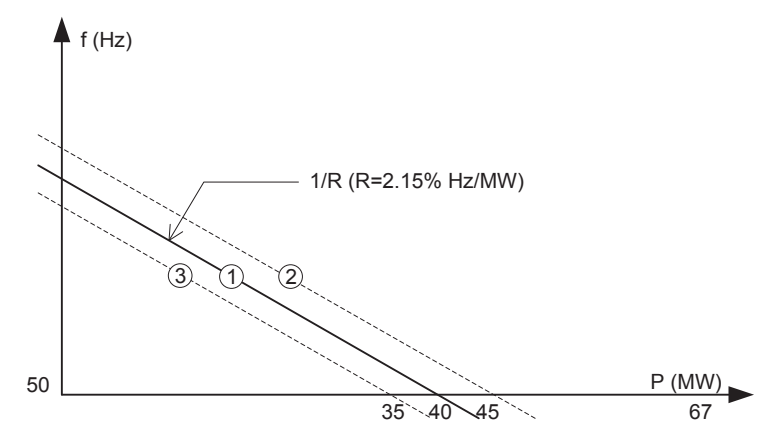

Figure 1 - Speed-droop characteristics of Kotmale Hydro Power Plant

When on frequency control, the power plant generally operates closer to the midpoint of its unit capacity range of 0 to $67 \mathrm{MW}$. When the 
demand increases or decreases and when the frequency decreases or increases as a result, the operating point is moved first along the normal droop characteristic curve (marked 1) and settles down at a point above or below the set point corresponding to $50 \mathrm{~Hz}$. When the steady state operating point moves along the droop characteristic curve (without a change in the speed reference), the wicket gate position is adjusted by the governor controller via hydraulic actuators which adjust the active power delivered by the generator. The wicket gate adjustment is done by an electromechanical governor driven by a PID controller sensing frequency deviation $(\Delta \mathrm{f})$.

After Kotmale and all other generators connected to the system have changed their outputs to match the change in the demand, the frequency would settle down at a new steady state value along curve " 1 ", which is different to $50 \mathrm{~Hz}$.

At that point, operators at the station on frequency control which is Kotmale in this case, adjust the "speed reference", or shift the droop characteristic curve in Figure 1 to another parallel line (either 2 or 3 ), until the frequency is brought back to $50 \mathrm{~Hz}$. Once the frequency is brought back to $50 \mathrm{~Hz}$ by Kotmale operator, all other stations that were on fixed load, would once again adjust their outputs to the points in the droop characteristic curve corresponding to the fixed outputs as requested by the SCC prior to the disturbance.

At Kotmale, the frequency controlling is performed by looking at the frequency error $\Delta \mathrm{f} \Delta \mathrm{F}$ and manually applying appropriate lower or raise commands to the control gear.

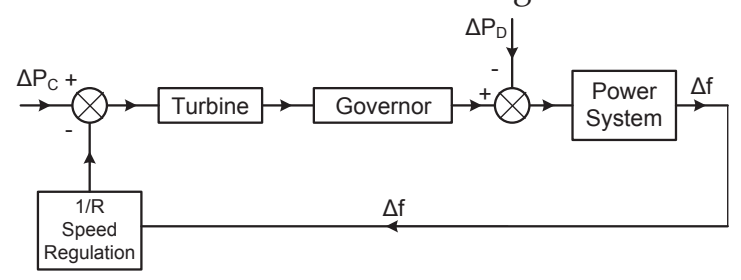

Figure 2 - Control Block Diagram of the Primary Load Frequency Controller

The block diagram of a typical primary load frequency controller is shown in Figure 2 where $\Delta \mathrm{P}_{\mathrm{C}}$ is the change to speed reference, $\Delta \mathrm{P}_{\mathrm{D}}$ is the change to system demand and $\Delta \mathrm{f}$ is the frequency error.

\section{Modeling of the existing Frequency Controlling System}

3.1 Transfer Functions

3.1.1 Governor Transfer Function

The Transfer Function of the electromechanical governor PID controller installed at Kotmale power plant, represented by the block titled "Governor" in Figure 2 can be represented by the transfer function (TF) [2]:

$T F=\frac{K_{d} \cdot s^{2}+K_{f} \cdot s+K_{i}}{K_{d} \cdot s^{2}+\left(K_{f}+\frac{f}{R}\right) \cdot s+K_{i}}$

where:

$\mathrm{K}_{\mathrm{d}}=$ Derivative gain $=2.9$

$\mathrm{f}=$ System frequency

$\mathrm{K}_{\mathrm{f}}=$ Proportional gain $=9.99$

$\mathrm{R}=$ Speed Regulation $=2.15 \%$

(While on frequency control)

$\mathrm{K}_{\mathrm{i}}=$ Integrator gain $=6.5$

\subsubsection{Turbine Transfer Function}

The Transfer Function (TF) of the vertical shaft Francis turbine installed at Kotmale power plant is:

$T F=\frac{-T_{w} \cdot s+1}{0.5 * T_{w} \cdot s+1}$

where:

$\mathrm{T}_{\mathrm{w}}=1$ second = Time constant of the hydro turbine

\subsubsection{Power System Transfer Function}

A power system can be represented by the typical transfer function (TF) [3]:

$$
T F=\frac{K_{p}}{T_{p} \cdot S+1}
$$

where:

$\mathrm{K}_{\mathrm{p}}=$ Power system gain

$\mathrm{T}_{\mathrm{p}}=$ Power system time constant

$$
K_{P} \stackrel{\text { def }}{=} \frac{1}{D} \quad D=\frac{\partial P_{D}}{\partial f}
$$

$P_{D}=$ Power Demand

$$
T_{P} \stackrel{\text { def }}{=} \frac{2 H}{f^{0} D}
$$

$f^{0}=$ Rated System Frequency 


\subsubsection{Computation of $K_{p}$ and $T_{p}$ for Sri Lankan Power System}

$\mathrm{K}_{\mathrm{P}}$ or power system gain has units of $\mathrm{Hz} / \mathrm{pu}$ MW, where pu MW is calculated taking the total rated system capacity as the base. As the total system demand varies, the total capacity of machines connected to serve the demand, which is higher than the total demand to meet spinning reserve requirement, also will vary. The chronological load curve of the Sri Lankan power system for a typical day is shown in Figure 3 . Here, approximately $5 \%$ of the reserve margin can be observed between the load and the total capacity of the connected generators.

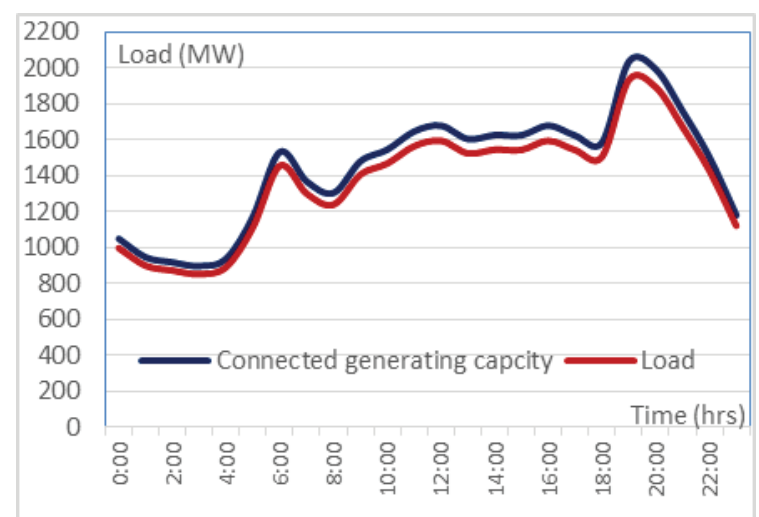

Figure 3 - Chronological Load Curve of Sri Lankan Power System

Owing to changes in the total rated capacity of machines connected to the system with time (and hence the MW base used to calculate $\mathrm{K}_{\mathrm{P}}$ ) and changes in the composition of loads, inertia constant of power system $(\mathrm{H})$ and the rate of change of load with respect to frequency (D) , $\mathrm{K}_{\mathrm{p}}$ and $\mathrm{T}_{\mathrm{p}}$, too vary with time. Thus, in this study, D is kept at its typical value of $1 \mathrm{pu}$ (meaning a $1 \%$ change in demand due to $1 \%$ frequency change) and $\mathrm{H}$ is assumed as 5 seconds.

$$
\begin{gathered}
D=1 p u M W / p u H z=0.019 p u M W / H z \\
K_{P}=52.63 \mathrm{~Hz} / p u M W \\
T_{p}=10.53 \mathrm{~S}
\end{gathered}
$$

However, once the system is modeled and fuzzy logic controller is designed, the response of same will be tested for different $\mathrm{D}$ values ranging from $1 \mathrm{pu}$ to $5 \mathrm{pu}$ and $\mathrm{H}$ from $5 \mathrm{~s}$ to $8 \mathrm{~s}$.

\section{Frequency Deviation with Load}

The behavior of the system frequency is simulated using MATLAB/SIMULINK software package with different step load changes at Kotmale hydro power station.
The block diagram of the simulation model is shown in Figure 4.

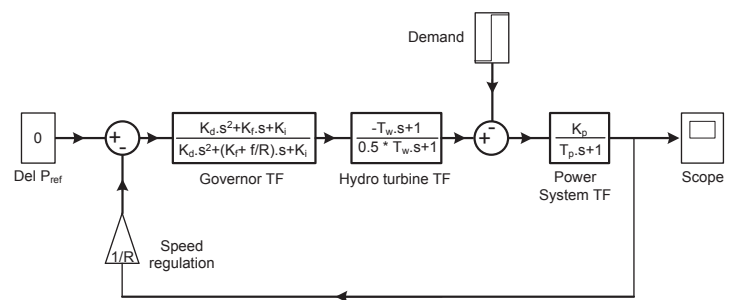

Figure 4 - Simulation Model for the Existing System

\subsection{Frequency Deviation with Step Load Change}

The maximum allowable frequency deviation of Sri Lankan power system is $1 \%$, i.e. $49.5 \mathrm{~Hz}-$ $50.5 \mathrm{~Hz}$. However, if the frequency error is allowed to remain even within this range, that could affect the quality of the output of some devices such as frequency dependent motor drives, microprocessor based equipment and even electric clocks. Thus, it is the primary responsibility of the utility to maintain its value close to the nominal value of $50 \mathrm{~Hz}$ as much as possible.

The frequency response of the system for 0.01 pu step increase in the load, is shown in Figure 5.

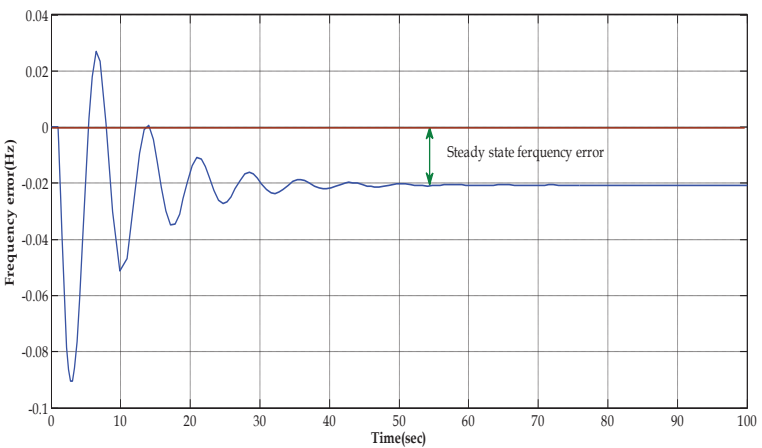

Figure 5 - Simulation of 0.01 pu Step Load Increase

Here a steady state error of $-0.02 \mathrm{~Hz}$ can be observed when the load is increased by $0.01 \mathrm{pu}$. Hence, a secondary loop controller is needed to maintain a steady state error-free frequency for better quality and a more reliable power system.

It has been found from recent studies that using artificial intelligence, more advanced controllers than conventional controllers can be designed. Hence, a fuzzy logic controller is 
used to control the secondary loop in this study.

\section{Fuzzy Logic Controller (FLC)}

\subsection{What is fuzzy control?}

Fuzzy logic is a problem solving technique found in the field of control system engineering. This technique has been widely used to control dynamic systems, especially when the inputs are either imprecise or when the mathematical models are not available. The fuzzy logic control design can be divided into three main areas, namely, identification of inputs, determination of rules and defuzzfication of output in to real values. [6].

\subsection{A Typical Fuzzy Control System}

There are two types of fuzzy systems, viz., Mamdani and Takagi Sugeno.

Mamdani System: Mamdani system expects the output membership functions to be fuzzy sets. After an aggregation process, a fuzzy set for each output variable that needs defuzzification can be computed.

Takagi Sugeno System: Takagi Sugeno system is similar to the Mamdani method in many respects. The first two parts of the fuzzy inference process, fuzzifing the inputs and applying the operators are exactly the same. The main difference between Mandani and Sugeno is that the Sugeno output membership functions are either linear or constant.

In this study, Mamdani type fuzzy inference system is employed because of its simplicity and intuitive characteristics, and also because it has been commonly used for computational problems with two inputs and one output.

\subsection{Operation Process of Mamdani FLC}

In contrast to conventional control techniques, Fuzzy Logic Control (FLC) is best utilized in complex and not so clearly described processes that can be controlled by a skilled human operator without much knowledge of system dynamics. The basic idea behind FLC is to incorporate the expert experience of a human operator in the design of the controller that controls a process whose input and output relationship is described by a collection of fuzzy control rules involving linguistic variables rather than a complicated dynamic model. [5]

The utilization of linguistic variables, fuzzy control rules and approximate reasoning provides a means to incorporate human expert experience in designing the controller.
A typical architecture of a Mamdani FLC is shown in Figure 6, which comprises three principal elements viz., the fuzzifier, fuzzy rule base and the defuzzifier.

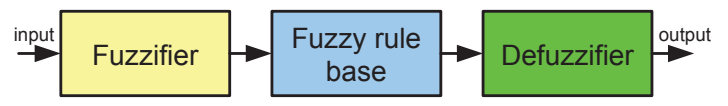

Figure 6 - Typical Architecture of a Mamdani FLC

Fuzzifier: Converts the crisp input to a linguistic variable using membership functions.

Fuzzy Rule Base: Using If-Then type fuzzy rules converts the fuzzy input to the fuzzy output.

Defuzzifier: Converts the fuzzy output of the inference engine to a crisp value.

\section{Design of the Proposed Fuzzy Logic Controller}

\subsection{Input Variables}

For load frequency changes, the process operator is assumed to respond to variables such as frequency error $(\Delta \mathrm{f})$ and the rate of change of frequency error $\left(\frac{d(\Delta f)}{d t}\right)$. They are the inputs to the FLC. A triangular-shaped membership function was used owing to its simple implementation and fast computation behavior. In this study, the following five triangular membership functions have been identified and applied :

NB - Negative big

NM - Negative medium

PM - Positive medium

PB - Positive big

ZE - Zero

\subsubsection{Membership Function of Frequency Error $(\Delta \mathbf{f})$}

The limits of the power system frequency error $(\Delta \mathrm{f})$ were decided based on the variation of the system frequency of the existing power system. This is shown in Figure 7. The universe of discourse is taken from -0.2 to 0.2 .

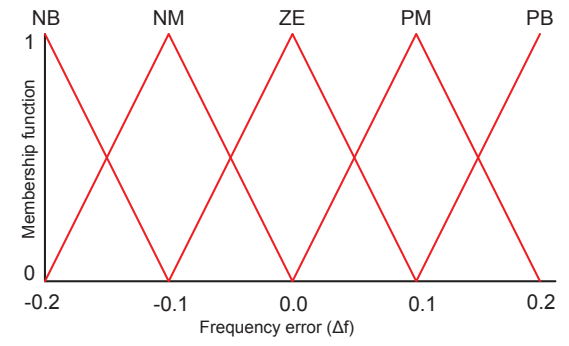

Figure 7 - Membership Functions of Input Variable for Frequency Error 


\subsubsection{Membership Function for Rate of Change of Frequency Error $\left(\frac{d(\Delta f)}{d t}\right)$}

Here, a derivative has to be used to predict the error in future, based on the current slope of the error. The limits of membership values are used to reflect the frequency error $(\Delta \mathbf{f})$ exactly. The universe of discourse here too is selected from 0.2 to 0.2 as shown in Figure 8 .

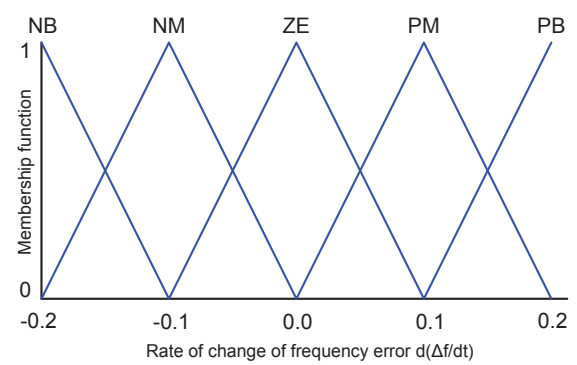

Figure 8 - Membership Functions of the Input Variable for the Rate of Change of Frequency Error

\subsection{Output Variable}

The output variable identified here is the reference power $\left(\Delta \mathrm{P}_{\mathrm{c}}\right)$.

\subsubsection{Membership Function of the Reference Power $\left(\Delta \mathbf{P}_{c}\right)$.}

Since the unit capacity of Kotmale power plant is $67 \mathrm{MW}$, the plant is initially loaded and retained at $27 \mathrm{MW}$ for the absorption of system load variations.

Universe of discourse selected here is from -0.1 to 0.1 as shown in Figure 9 below.

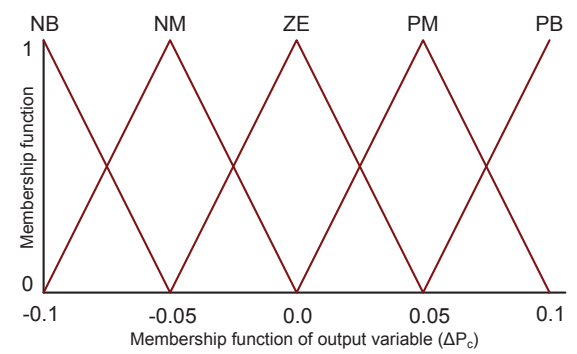

Figure 9 - Membership Functions of the Output Variable $\left(\Delta \mathbf{P}_{\mathrm{c}}\right)$

\subsection{Fuzzy Control Rules}

Fuzzy control rules can be considered as the knowledge of an expert in any related field of application. The fuzzy rule is represented by a sequence of IF-THEN, leading to algorithms describing what action or output should be taken in terms of the currently observed information, which includes both inputs and feedback if a closed-loop control system is applied.

\subsubsection{Fuzzy Inference Rule for the Proposed Controller}

In this study, input and output membership functions are same and five segment triangular membership functions are used as stated earlier. Since each input has five membership functions, the number of fuzzy based rules is twenty five and they are presented in Table 1.

Table 1 - Fuzzy Inference Rule set for FLC

\begin{tabular}{|c|c|c|c|c|c|c|}
\hline $\begin{array}{c}\text { Input } \\
\text { Variables }\end{array}$ & \multicolumn{6}{|c|}{$(\Delta \mathbf{f})$} \\
\hline \multirow{4}{*}{$\downarrow$} & & NB & NM & ZE & PM & PB \\
\cline { 2 - 7 }$\downarrow$ & NB & NB & NB & NB & NM & ZE \\
\cline { 2 - 7 } $\boldsymbol{d}(\Delta \mathbf{f})$ & NM & NM & NB & NB & NM & ZE \\
\cline { 2 - 7 } $\boldsymbol{d} \boldsymbol{t}$ & ZE & ZE & NM & NM & ZE & PM \\
\cline { 2 - 7 } & PM & PM & ZE & PM & PM & PB \\
\cline { 2 - 7 } & PB & PB & ZE & ZE & PM & PB \\
\hline
\end{tabular}

\subsection{Defuzzification}

The last step in the fuzzy inference process is defuzzification. Fuzziness helps us to evaluate the rules, but the final output of a fuzzy system has to be a crisp number.

The input for the defuzzification process is the aggregate output fuzzy set and the output is a single number. There are several defuzzification methods, but the most popular one probably is the centroid technique.

It finds the point where a vertical line would slice the aggregate set into two equal masses. Mathematically this is identified as the Centre of Gravity (COG).

\section{Results (Simulation of FLC)}

A steady state frequency drop of $0.02 \mathrm{~Hz}$ was observed earlier when a system disturbance of 0.01 p.u step load is applied to the existing power system and it requires a secondary control loop to eliminate same. The proposed fuzzy logic controller is introduced here as a secondary loop controller to see its performance characteristics.

\subsection{Simulation Block Diagram for Frequency Control with the Proposed FLC}

The proposed fuzzy logic controller could be connected to the existing power system as a secondary control loop to eliminate steady state frequency error. The block diagram of the frequency controller using FLC is shown as Figure A1 in the Appendix.

However, to eliminate over shoots, under shoots and to achieve fast and smooth response, 
Kotmale power plant governor PID control parameters have to be closely examined and fine-tuned. Such fine-tuned parameters for PID governor controller at Kotmale power station is shown in Table 2.

Table 2 - Fine-Tuned Values of PID Controller

\begin{tabular}{|c|c|}
\hline Parameter & Value \\
\hline $\mathrm{K}_{\mathrm{d}}$ & 4.8 \\
\hline $\mathrm{K}_{\mathrm{f}}$ & 8 \\
\hline $\mathrm{K}_{\mathrm{i}}$ & 2.5 \\
\hline
\end{tabular}

The frequency deviation after introducing the secondary loop fuzzy logic controller is shown in Figure 10. It should be noted that the steady state frequency error has been damped out and smoothly eliminated here.

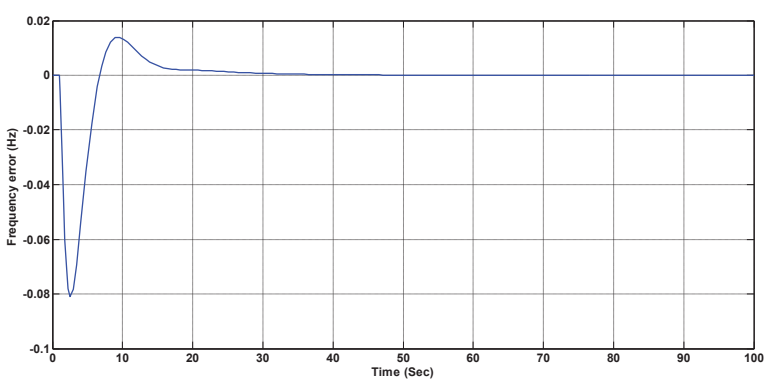

Figure 10 - Frequency Response for a Step Load Change after introducing Fuzzy Logic Controller as a Secondary Loop

\subsection{Comparison of Frequency Deviation with and without FLC}

It can be seen from both simulations that the proposed fuzzy logic controller gives better performance with a zero steady state error compared with the existing primary load frequency controlling method installed at Kotmale power station. This is shown in Figure 11 for better comparison. The response of the system tested for different $\mathrm{D}$ values ranging from 1 to 5 and $H$ values ranging from $5 S$ to $8 S$ is shown in Appendix as Figure B-1 to B-4.

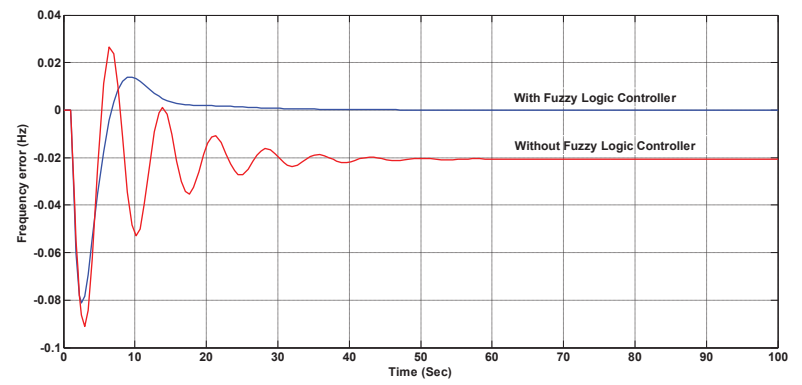

Figure 11 - Comparison of Frequency Deviation with and without FLC

\section{Conclusion}

It is revealed from this study that the introduction of fuzzy logic to the secondary loop controller not only completely eliminated the steady state frequency error but also improved the dynamic response of the frequency controlling quality on the basis of dynamic parameters such as settling time, overshoots and undershoots and that the same can be effectively used to replace the manual operator-controlled frequency controlling method used at Kotmale power plant.

The proposed frequency controlling method with fuzzy logic can be applied to other power frequency controlling power plants as well which contribute to controlling the steady state frequency error at different times.

\section{Acknowledgement}

The authors would like to offer their appreciation to Eng. A. K. Samarasinghe, AGM Generation, Eng. Nizan Salih, Maintanance Engineer, Kotmale (2008-2012) \& now CE, Uthuru Janani power station and Eng. Ramindu Karunaratne, SCC, all of Ceylon Electricity Board for their assistance in providing facilities for this research study. Many thanks for the helpful comments suggestions and the guidance provided by Dr. Narendra de Silva of LECO and Mr. C. J Basnayakage/Mr. G. Anthony Senior Lectures of the Open University of Sri Lanka

\section{References}

1. Kothari, D. P. Nagrath, I. J. 2009, Modern Power System Analysis, Third Edition, India: Tata McGraw Hill Education Private Limited.

2. Muhammad Ahsan Zamee, Dipankar Mitra, Sadaf Yusuf Tahhan. Load Frequency Control of Interconnected Hydro-Thermal Power System Using Conventional PI and Fuzzy Logic Controller. International Journal of Energy and Power Engineering. Vol. 2, No. 5, 2013, pp. 191196

3. Kundur, P., 1994. Power System Stability and Control, Mc Graw hill New York

4. Panda, A. M., Automatic Generation Control of Multi Area Interconnected Power System Considering Non-Linearity. Archives of control science, 7, pp 285-299, 1998

5. Ramanand Kashyap, Prof. S. S. Sankeswari, Prof. B. A. Patil, Load frequency control using fuzzy 
PI controller generation of interconnected hydropower system, International Journal of Emerging Technology and Advanced Engineering, ISSN 2250-2459, ISO 9001:2008 Certified Journal, Volume 3, Issue 9, September 2013

6. Mathwork, Simulink tutorial, Available at http://in.mathworks.com/products/simulinkreal-time/?s_tid=hp_fp_list
[Accessed: 2nd February 2015]

7. Ceylon Electricity Board, 2012, CEB- Annual Reports, Available

at: http://www.ceb.lk/sub/publications/annual.a spx [Accessed: 22nd January 2015]

\section{Appendix}

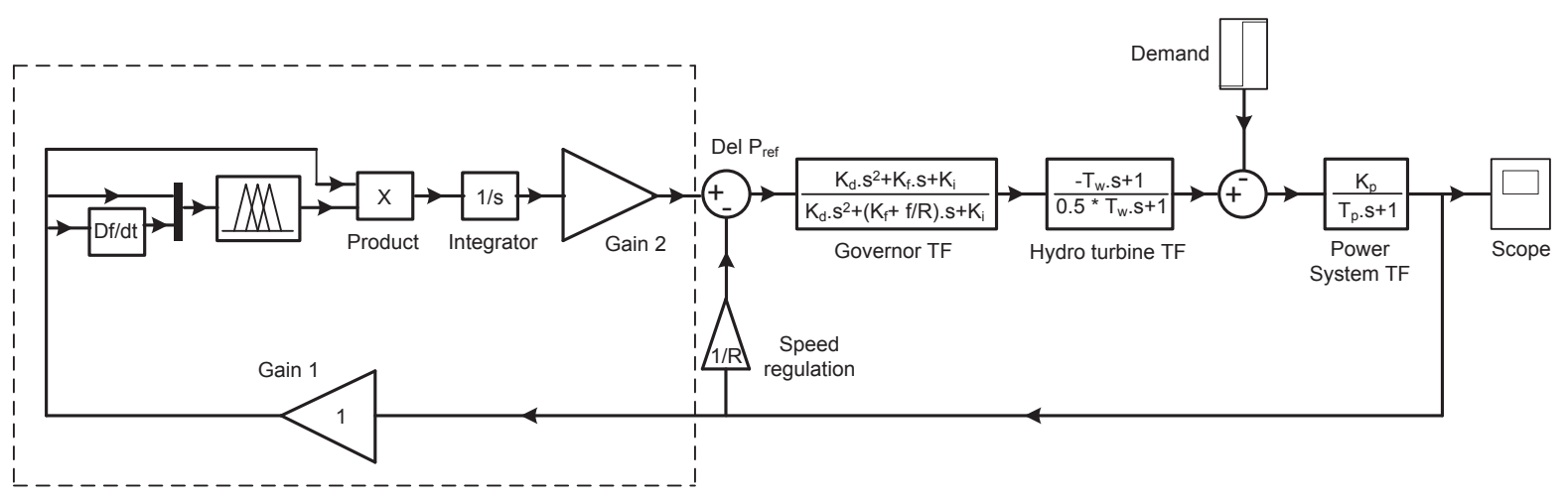

Figure A1 - Simulation Block Diagram for Frequency Control with the Proposed Fuzzy Logic Controller

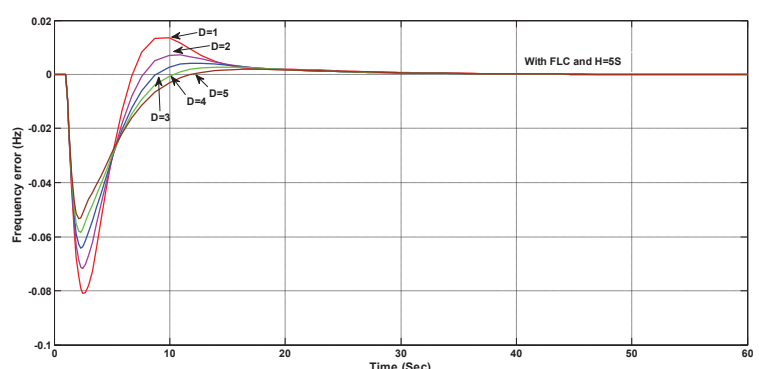

FigureB1-Response for $\mathrm{H}=5 \mathrm{~s}$ and $\mathrm{D}=1-5$

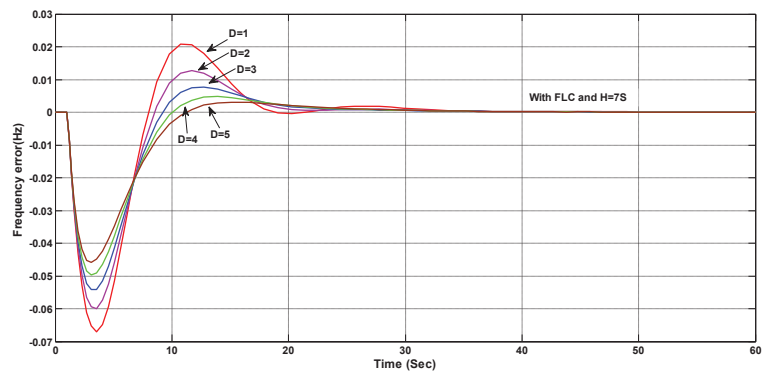

Figure B3-Response for $\mathrm{H}=7 \mathrm{~s}$ and $\mathrm{D}=1-5$

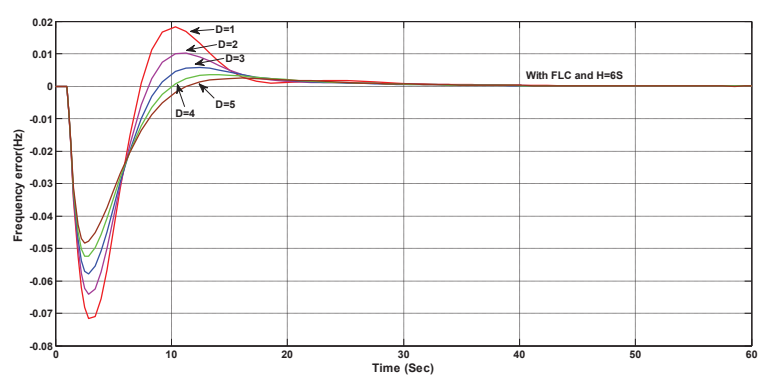

Figure B2-Response for $\mathrm{H}=6 \mathrm{~s}$ and $\mathrm{D}=1-5$

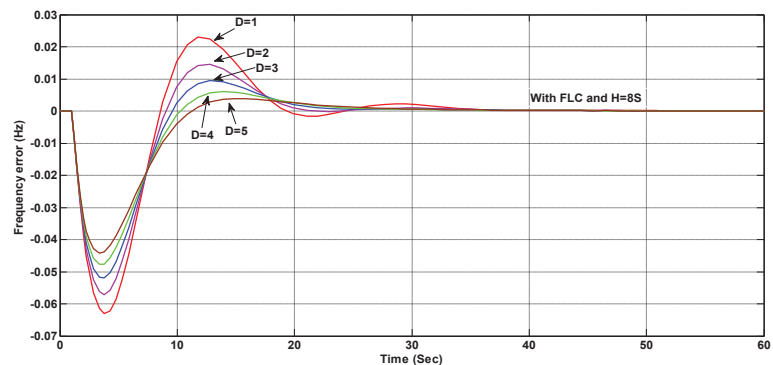

Figure B4-Response for $\mathrm{H}=8 \mathrm{~s}$ and $\mathrm{D}=1-5$ 